\title{
OLOR A ESCUELA
}

Gustavo Bombini ${ }^{1}$

Mirta Gloria Fernández ${ }^{2}$

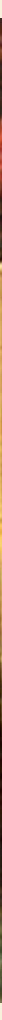

1 Doctor en Letras. Profesor e investigador en Didáctica de la Lengua y la Literatura, y Literatura Infantil. Universidad de Buenos Aires y Universidad Nacional de San Martín. Correo electrónico: gbombini@gmail.com ORCID https://orcid.org/0000-0003-3017-7846

2 Magíster en Análisis del Discurso. Profesora e investigadora en Didáctica de la Lengua y la Literatura, y Literatura Infantil. Universidad de Buenos Aires y Universidad Nacional de San Martín. Correo electrónico: titiludu@gmail.com ORCID https://orcid.org/0000-0002-7518-7047

Cómo citar: Bombini, G., Fernández, M. G. (2020). Olor a escuela. Enunciación, 25(2, separata), XXII-XXV. https://doi.org/10.14483/22486798.17016 
L a frase ya cristalizada dar clase podría resultar insuficiente para referirnos a nuestra modalidad pedagógica en el aula, que se vincula más bien con el interactuar, el construir, el colaborar, el orientar, más que con el otorgar, el proporcionar, el brindar, el donar. Acaso podríamos inventar el verbo darclasear, si se nos permite la licencia. Y ya sabemos todos que darclasear no abarca cierto sentido de reciprocidad que caracteriza a una clase.

La premura y acaso la ansiedad por re-encontrarnos y empezar a trabajar con nuestros alumnos en el perturbador mundo de la pandemia nos obligó a reinventar las formas en que daríamos clase. Con urgencia tuvimos que dejar atrás las pizarras, las volteretas corporales entre los pequeños pasillos que dejan los bancos, los cómodos apeos en un escritorio que soporta desde la mochila hasta la campera, desde la computadora hasta un celular puesto en silencio; de pronto toda materialidad se desvaneció: los juegos con el lapicero, el polvo de la tiza o la tinta del fibrón manchándonos las manos. La mirada hacia cada uno que nos devolvía la pregunta de una voz curiosa, la sonrisa del entusiasta, el chiste del oportuno, el entrecejo fruncido del pensativo. De pronto, habíamos perdido contacto con nuestro ahora más entrañable que nunca darclasear.

Fue de este modo que, ante la ausencia de cuerpos y materialidades, la virtualidad se presentó como la única opción posible para lo que se denominó continuidad pedagógica.

Y si se esfuman los cuerpos y se disuelve la materialidad: ¿Qué es entonces lo que queda? Quedan las palabras, podríamos responder e inmediatamente agregar: nunca tuvieron tanta importancia las palabras como en estos tiempos en los que darclasear se constituye a partir en un híbrido de audios, videos con contenidos urgentes, un Zoom por semana, un chat que funciona paralelamente a la clase, un WhatsApp por las dudas y, en algunos casos, el ejercicio de la escritura en la virtualidad, como modo de construir conocimiento en modo sincrónico -compartiendo lecturas de las escrituras a través de la oralidad-, o en modo asincrónico -compartiendo lecturas de las escrituras a través de la escritura-. Tal es nuestra experiencia de trabajo en aulas virtuales de la universidad, incluso antes de la pandemia.

Entre cuerpos diluidos, reemplazados en el mejor de los casos por mosaicos de caras congeladas, la palabra pasa a ser en sí misma el acto de enseñanza. Pero ¿nada más?, ¿con eso alcanza? Con alumnos con los que nunca hemos tenido contacto, ¿cómo hacerles saber quiénes somos? ¿Nos reconocen? ¿Saben que estamos ahí acompañándolos, aunque se hayan diluido los cuerpos? ¿Cómo explicarlo sin los cuerpos?

En el campus virtual de nuestra cátedra "Didáctica especial y prácticas de la enseñanza en letras", de la Facultad de Filosofía y Letras de la Universidad de Buenos Aires, cada uno de los doce profesores que la integran elige una modalidad estética de presentación de su propio espacio; se ven unas pinturas abstractas, la foto de unas piernas abigarradas calzando zapatillas con estilo adolescente o una obra del artista plástico argentino Antonio Berni, que muestra a unos niños en una escuela rural. Desde ese marco cada uno le habla a su grupo de veinte futuros profesores. Cada semana una consigna, resuelta en grupo, va conectando a los alumnos entre sí. Se arman dúos o tríos, y la producción escrita fluye. Las tareas propuestas por las consignas llegan en tiempo y forma, y unos evacuan sus dudas a través de mensajes de WhatsApp, otros agradecen los audios enviados por el docente a través de emoticones, algunos hacen comentarios apropiados sobre las correcciones hechas a su producción. Después de tres meses de cursada, son evaluados y escriben unos exámenes parciales interesantes. Aparecen en los Zoom, hacen preguntas, formulan ideas, se quedan hasta el final de la clase y escriben en el chat paralelo a la clase virtual. Nadie se pierde, como temíamos, en la imaginada espiral de la virtualidad. Y en el mientras tanto hasta la escritura se transforma en cuerpo. Se in-corpora. Entre cuerpos diluidos o mosaicos de caras congeladas, las 
palabras, por sí mismas, pasan a ser el acto de comunicación más preciado. Hasta aparece la palabra poética desde la consigna de glosar el "Poema del manicomio", del poeta peruano Carlos Oquendo de Amat (1905-1936) (tabla 1).

Pero por sobre la función poética del lenguaje, se presenta de manera más frecuente la función fática (o de contacto) -del tan escolarizado esquema de Roman Jakobson- y las preguntas se suceden: “¿Están viendo el PowerPoint?”; “¿Se cortó otra vez?”; “¿Me están escuchando?”; “¿Están ahí todavía?, háganme una seña, pero no abran los micrófonos". Ruido metálico y algo cavernoso, como si nos encontráramos frente a dimensiones desconocidas. De pronto, silencio absoluto. De un mosaico de caras congeladas a veces se desprende una u otra voz que contesta: "Sí, profe, se ve el Power"; "Estamos acá, no se preocupe". Escribir es hoy una práctica que nos permite configurarnos como alumnos y como profesores, desde donde podemos ratificar nuestra identidad, acaso desdibujada por el confinamiento de nuestros cuerpos en el acotado espacio de nuestros domicilios.

Frente a la pura visibilidad de los encuentros en Meet, en Zoom o en el canal de Facebook, nos resistimos a entrar en contacto con esas cabecitas meramente asintiendo, no queremos construir una audiencia ni una legión de admiradores, no somos rock stars. Queremos seguir sosteniendo que la construcción del conocimiento se produce de manera compartida, y para eso la teleconferencia es insuficiente y se asemeja, incluso, a la clase magistral en aquellos viejos términos hace ya tiempo descartada de nuestras prácticas. La construcción del saber se funda en un trabajo cooperativo, de diálogo, de oralidad, anclado en cierta actitud teatral,

Tabla 1. Interpretación del poema de Oquendo de Amat por las estudiantes Pía, Victoria y Lara

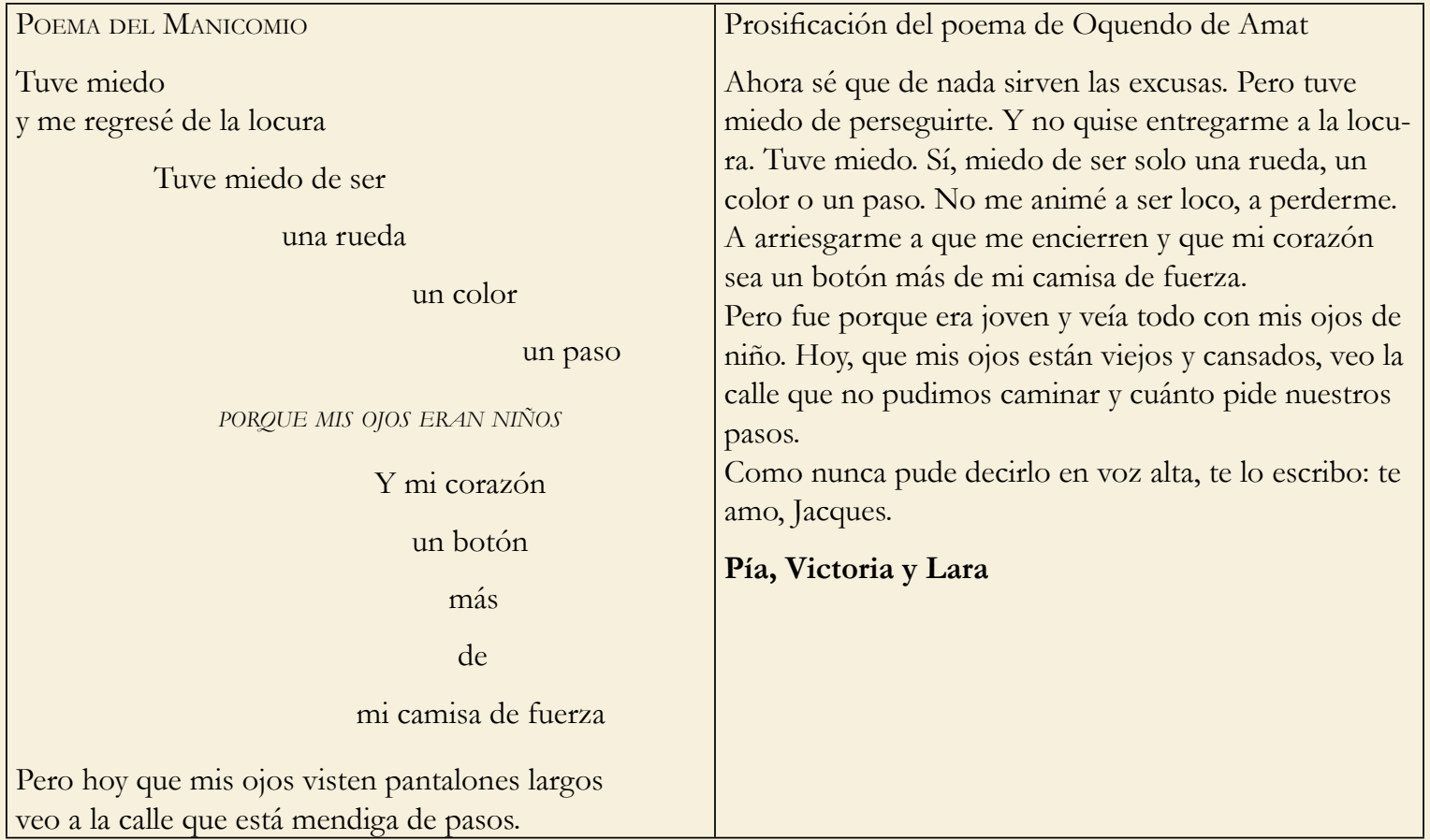

Fuente: elaboración propia. 
que es propia de la presencialidad, del orden del cuerpo. Tanto nos ha costado reconocer la dimensión del cuerpo a lo largo de la historia de la escuela: cuerpo disciplinado, controlado, censurado, uniformado bajo el guardapolvo u otra vestimenta; cuerpo en la obligación de asumir una posición determinada en la lectura (cómo se debían apoyar los pies, cómo se levantaba la cabeza, cómo se tomaba el libro, cómo se daban vuelta las páginas). Hemos encontrado muchas prescripciones acerca del uso del cuerpo en escritos de pedagogos positivistas de principios del siglo $\mathrm{XX}$-en vísperas de la fundación de los sistemas educativos nacionales-, textos que hablan de que ese control de la corporeidad ha sido muy importante en la escuela, de que su paulatino reconocimiento y liberación fue parte de las luchas del siglo XX y ahora, repentinamente, nuestra tarea de dar clases se produce con la dimensión de lo corporal negada. Fuimos desalojados de nuestras aulas y de ellas fueron desalojados nuestros cuerpos, reducidos ahora a esas cabecitas que asienten en forma de mosaico. Inevitable contrariedad: habíamos aprendido a aceptar a nuestros cuerpos, a todos los cuerpos los que ahora son brutalmente negados.

Habíamos descubierto además que la escuela siempre se valió de varios órdenes en su modo de transmitir el conocimiento, es decir, que siempre fue multimodal, en el sentido de que el maestro da su clase en una posición histriónica, teatral, en su mejor escenario que es el aula, un escenario cuya decoración son las láminas: la vieja lámina del aparato digestivo, el correspondiente mapa para la clase de geografía o el retrato de prócer que se homenajea en ese mes; y también son parte de ese escenario, las más o menos prolijas escrituras en el pizarrón que van acompañando y graficando las explicaciones. Se trató siempre de una alianza interesante, y por cierto compleja, entre la cultura letrada (que es la lectura, la escritura y también la oralidad como forma principal para la mediación en el aula y como interfase entre lo escrito, lo sonoro, lo visual, lo audiovisual.

¿Será que en el horizonte audiovisual del Zoom o del Meet, en la representación a pequeña escala que nos brinda la pantalla de nuestra notebook, o en la más pequeña aún de nuestro celular, abrigamos la ilusión de recuperar algo de aquellas añoradas ya articulaciones entre escritura, lectura, oralidad, imagen fija, imagen en movimiento, sonido? ¿Será que ahí se produce lo más parecido a esa presencialidad perdida por un lapso cuya duración todavía desconocemos?

Decíamos más arriba que la escritura es ahora una forma de corporeidad, en el sentido de hacernos presentes a través de ella; sabemos que esto es potente pero no suficiente. Por eso, a la vez, venimos experimentando estos modos de contacto en pantalla de los que a veces no sabemos muy bien cómo se sale: ¿'Toca encender el micrófono y agradecer la clase y despedirse?: eso no lo hacemos en la presencialidad, luego de que hemos estado mirándonos a través de las pantallas acaso por un largo tiempo con los micrófonos silenciados (para mejorar la calidad de la comunicación y para evitar interferencias). También recurrimos a grupos de WhatsApp para agilizar la comunicación y hemos evacuado dudas por esa vía aún en audios que luego descubrimos que han sido altamente valorados por nuestros estudiantes por su claridad.

Pero al fin, lo que nos falta es de orden sensorial, acaso un universal que sería lo que podríamos llamar olor a escuela. Nos gusta esa imagen, porque suma otra dimensión sensitiva a nuestra aula multimodal. Y, precisamente, en el contexto de la cuarentena, ya no hay olor a escuela y esto nos plantea más interrogantes respecto a la pregunta que nos hacíamos al principio: ¿Qué es dar clase?

\section{(c) $(1)(\odot)$}

